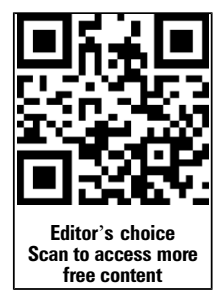

${ }^{1}$ Emergency Department, Derriford Hospital, Plymouth, UK

${ }^{2}$ Centre for Clinical Trials and Population Studies, Plymouth University Peninsula Schools of Medicine and Dentistry, Plymouth, UK

${ }^{3}$ Academic Department of Military Emergency Medicine, Royal Centre for Defence Medicine (Research \&

Academia), Medical Directorate, Birmingham, UK

${ }^{4}$ Trauma Audit Research Network (TARN), University of Manchester, Hope Hospital, Salford, UK

${ }^{5}$ EMRiS Group, Health Services Research Section, School of Health and Related Research, University of Sheffield, Sheffield, UK

\section{Correspondence to}

Dr Anthony Kehoe, Emergency Department, Derriford Hospital, Plymouth, UK;

tony.kehoe@nhs.net

Received 27 July 2015 Revised 9 December 2015

Accepted 29 December 2015 Published Online First 29 January 2016

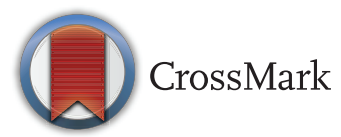

To cite: Kehoe A, Smith JE, Bouamra 0 , et al. Emerg Med J 2016:33:381-385.

\title{
Older patients with traumatic brain injury present with a higher GCS score than younger patients for a given severity of injury
}

\author{
A Kehoe, ${ }^{1,2}$ J E Smith, ${ }^{1,2,3}$ O Bouamra, ${ }^{4}$ A Edwards, ${ }^{4}$ D Yates, ${ }^{4}$ F Lecky ${ }^{4,5}$
}

\begin{abstract}
Introduction Recent evidence suggests that presenting GCS may be higher in older rather than younger patients for an equivalent anatomical severity of traumatic brain injury (TBI). The aim of this study was to confirm these observations using a national trauma database and to test explanatory hypotheses.

Methods The Trauma Audit Research Network database was interrogated to identify all adult cases of severe isolated TBI from 1988 to 2013. Cases were categorised by age into those under 65 years and those 65 years and older. Median presenting GCS was compared between the groups at abbreviated injury score (AIS) level (3, 4 and 5). Comparisons were repeated for subgroups defined by mechanism of injury and type of isolated intracranial injury.
\end{abstract}

Results 25082 patients with isolated TBI met the inclusion criteria, 10936 in the older group and 14146 in the younger group. Median or distribution of presenting GCS differed between groups at each AIS level. AIS 3: 14 (11-15) vs 15 (13-15), AIS 4: 14 (9-15) vs 14 (13-15), AIS 5: 9 (4-14) vs 14 (5-15) all $p<0.001$. Similar differences between the groups were observed across all mechanisms of injury and types of isolated intracranial injury. We detected no influence of gender on results.

Conclusions For an equivalent severity of intracranial injury, presenting GCS is higher in older patients than in the young. This observation is unlikely to be explained by differences in mechanism of injury or types of intracranial injury between the two groups.

\section{INTRODUCTION}

Traumatic brain injury (TBI) is common, affecting approximately 10 million people annually worldwide. ${ }^{1}$ The severity of TBI is traditionally classified according to the GCS at presentation into mild (GCS 13-15), moderate (GCS 9-12) and severe (GCS $\leq 8$ ). ${ }^{2}$ Historically, these have been considered thresholds defining groups suffering progressively increasing mortality ${ }^{3}$ and hence admission GCS is one of the major factors directing neurosurgical decision-making. ${ }^{4}$ This influences the decision to transfer a patient to a neurosciences centre and also guides the requirement for neurosurgical intervention.

Ageing populations in Western societies have resulted in an increase in the incidence of major trauma in the elderly. ${ }^{5}$ National guidelines for the investigation of patients with TBI have driven more widespread use of computed axial tomography, which has improved the detection rate of TBI. ${ }^{6}$

\section{Key messages}

What is already known on this subject?

- Two relatively small studies have been published suggesting that presenting GCS is higher in older patients for an equivalent isolated traumatic brain injury (TBI).

- It was suggested that this observation may have been due to different mechanisms of injury or type of intracranial injury more commonly observed in older patients.

What might this study add?

- This large study using prospectively collected data for $>25000$ patients with isolated TBI confirms that presenting GCS is higher in older patients at each level of injury severity, regardless of mechanism or type of intracranial injury.

- The difference is more apparent towards the more severe end of the injury spectrum.

- These findings have implications for outcome modelling in trauma and for triage guidelines that use GCS as a criterion.

Thus, in the UK, in recent years there has been a surge in the reporting of TBI in the elderly, which is becoming increasingly recognised as one of the most significant threats to life and well-being in older age. ${ }^{1}$

The management of elderly patients with TBI is controversial and challenging. ${ }^{7}$ Although it has been well established that, in general, outcomes following TBI are worse in the elderly than in the young, studies from several centres describe encouraging results from neurosurgical intervention and aggressive rehabilitation even in the extreme elderly. ${ }^{8-11}$

The field triage of older patients with TBI is, therefore, important so that those who may benefit from early treatment in a major trauma centre (MTC) are taken there directly from scene. Many field triage guidelines are based on a combination of anatomical injury, mechanism of injury and vital signs (including GCS). The sensitivity of such tools for identifying major trauma has been reported to decrease with age. ${ }^{12}$ Recent work by ourselves and others suggests that for a given anatomical severity of TBI, the elderly may present with a higher GCS than younger patients. ${ }^{13}{ }^{14}$ This may partly explain the poor performance of triage tools in the elderly. 
The reasons behind the observation are as yet unclear. Older patients with TBI are more likely to be female, to have been injured in a low-energy fall and to have suffered a subdural haematoma than their younger counterparts, which, it is suggested, may explain the observed difference in presenting GCS. ${ }^{13}$ The aim of this study was to explore the relationship between age and presenting GCS in a much larger data set to confirm these findings and to explore potential underlying mechanisms in more detail.

\section{METHODS}

We interrogated the Trauma Audit Research Network (TARN) database to identify all patients in England presenting with isolated TBI between 1988 and 2013. Data included age, gender, mechanism of injury, abbreviated injury score (AIS) head, outcome, type of TBI (extradural, subdural, subarachnoid haemorrhage, parenchymal contusion) and GCS on arrival at hospital. Patients were categorised into elderly (65 years and older) and young ( $<65$ years), and GCS was compared between these groups for each grade of AIS head injury severity. To investigate potential explanations for any observed differences between the two groups, secondary analyses comparing differences in median GCS for specific mechanisms of injury and specific types of TBI were also performed. Thirty-day all-cause mortality is recorded in the TARN database.

\section{INCLUSION/EXCLUSION CRITERIA}

Cases were included if they were $>16$ years of age at the time of injury and had suffered an isolated, blunt head injury (defined as any AIS head code with a severity of 3-5, excluding any patients with injuries to other body region attracting an AIS $>2$ ). Cases were direct admissions from scene of injury only.

TARN eligibility includes trauma patients who are admitted to hospital for $\geq 72 \mathrm{~h}$, are admitted to a critical care unit, die in hospital or are transferred to another hospital for specialist care.

Cases were excluded if evidence of drug or alcohol intoxication, smoke or fume inhalation, psychiatric disturbance or traumatic asphyxia had been recorded.

\section{STATISTICAL ANALYSIS}

As GCS distribution was skewed, median and distributions of GCS were compared between the two groups at each level of AIS severity overall and for each mechanism of injury in isolation.

Subgroups with specific intracranial injuries were also identified and GCS compared in the same way between the two groups for each intracranial injury type. Comparison of GCS between the two groups was performed using the MannWhitney test. ${ }^{15}$

While this test is most usually performed to compare medians, it may also be used to compare distributions between two groups. ${ }^{16}$ Caution must be employed when using the Mann-Whitney test to compare distributions of values between two groups that have the same median. With large groups, small differences in the shape or breadth of distribution can appear significant. The IQR provides a guide to whether or not any difference is clinically significant.

\section{RESULTS}

In total, 25082 patients with isolated TBI met the inclusion criteria and were considered in the analysis. The baseline characteristics are presented in table 1 . In total, 14146 in the younger group ( $<65$ years) and 10936 cases were in the older group (65 years and older). Patients in the older group with TBI were on average 44 ( 81 vs 37 ) years older than the younger cohort and older adults more frequently had the most severe form of TBI (40\% vs $30 \%$ of cases with AIS 5 severity). The majority of older patients with TBI (70\%) were injured by a low-energy fall, whereas this was the causal mechanism in only $20 \%$ of younger patients. Overall mortality was almost three times higher in older patients $(28.4 \%$ vs $10.5 \%)$ despite the median presenting GCS in this group being higher (14 vs 13). Presenting GCS differed significantly between the groups at each level of injury severity with the greatest difference apparent at the highest injury severity (AIS 5) (table 2). This difference was consistently reproduced across each mechanism of injury analysed (table 2).

Analysis according to specific type of intracranial injury revealed a similar pattern, although the effect was reduced by the smaller numbers yielded by the stricter inclusion criteria. Significant differences in median initial GCS were, nonetheless, observed at one or more AIS level for each type of intracranial injury. For patients with multiple combinations of these injuries, the difference in GCS was again most apparent at the highest level of severity of injury (table 3 ).

Stratification of tables 2 and 3 by gender did not change the results (data not shown).

\section{DISCUSSION}

This study has identified that for a given anatomical severity of TBI, older patients present with a higher GCS than their younger counterparts, a difference that is more apparent with increased anatomical injury severity. This confirms and extends our own and other recently published findings in smaller studies, which found that elderly patients are less likely to present with a low GCS (3-8) for a given TBI severity. ${ }^{13} 14$

Our findings are particularly important for two reasons. First, GCS is used in most field triage guidelines to identify patients likely to need care in a specialist neurosurgical facility or MTC. ${ }^{17}$ In a recent study involving several trauma centres on the West Coast of North America, Nakamura et al ${ }^{12}$ found a progressive decrease in the sensitivity of their field triage guidelines for recognising major trauma with each decade of life beyond 60 years. In Ohio, Caterino et al studied the impact of increasing the triage guideline threshold of GCS from 13 to 14 in the elderly (defined as $>70$ years). They found that a GCS threshold of 13 resulted in a sensitivity for identifying clinically important TBI of only $27 \%$ in the elderly compared with $53 \%$ in younger adults. Increasing the GCS threshold to 14 in the elderly improved sensitivity to $42.7 \%$ while returning specificity to the same level as a GCS threshold of 13 in younger adults. They also found that in contrast to younger patients, a decrease of GCS from 15 to 14 in elderly patients with trauma was associated with a significant increase in mortality (OR 1.4). Mortality for elderly patients with a GCS of 14 exceeded that of younger adults with a GCS of $13 .{ }^{18}$ The adoption of field triage criteria specifically for the older population has significantly improved the ability to detect elderly patients needing MTC care. ${ }^{19}$

This study suggests that trauma systems may need to be adapted to ensure early recognition of significant TBI in the elderly population. There certainly needs to be an awareness of the findings of this study, with the potential for under-triage of elderly patients with TBI on the basis of normal or near-normal GCS. There are currently no nationally accepted triage criteria for major trauma with each UK regional trauma network adopting its own, although many derive ultimately from the American field triage guidelines. These do include age as a fourth-level 
Table 1 Characteristics of study patients

\begin{tabular}{|c|c|c|c|c|}
\hline & $\mathbf{N}$ & Age under 65 & $\mathbf{N}$ & Age 65 or older \\
\hline All patients & 14146 & & 10936 & \\
\hline \multicolumn{5}{|l|}{ Demographics } \\
\hline Male & 11006 & $77.8 \%(77.1 \%$ to $78.5 \%)$ & 5529 & $50.6 \%(49.6 \%$ to $51.5 \%)$ \\
\hline Age & & $37.0(24.9-50.3)$ & & $81.3(74.8-87.0)$ \\
\hline Presenting GCS & & $13(8-15)$ & & $14(11-15)$ \\
\hline Underwent surgical procedure & 1339 & $9.5 \%(9.0 \%$ to $9.9 \%)$ & 451 & $4.1 \%(3.8 \%$ to $4.5 \%)$ \\
\hline \multicolumn{5}{|l|}{ Injury severity } \\
\hline ISS & & $17(14-25)$ & & $18(16-25)$ \\
\hline Head AIS & & $4(3-5)$ & & $4(4-5)$ \\
\hline \multicolumn{5}{|l|}{ Highest AIS head } \\
\hline 3 & 4611 & $32.6 \%(31.8 \%$ to $33.4 \%)$ & 1881 & $17.2 \%(16.5 \%$ to $17.9 \%)$ \\
\hline 4 & 5365 & $37.9 \%(37.1 \%$ to $38.7 \%)$ & 4640 & $42.4 \%(41.5 \%$ to $43.4 \%)$ \\
\hline 5 & 4170 & $29.5 \%(28.2 \%$ to $30.2 \%)$ & 4415 & $40.4 \%(39.5 \%$ to $41.3 \%)$ \\
\hline \multicolumn{5}{|l|}{ Mechanism of injury } \\
\hline Fall $<2 \mathrm{~m}$ & 2865 & $20.3 \%(19.6 \%$ to $20.9 \%)$ & 7619 & $69.7 \%(68.8 \%$ to $70.5 \%)$ \\
\hline Fall $>2 \mathrm{~m}$ & 2485 & $17.6 \%(16.9 \%$ to $18.2 \%)$ & 1819 & $16.6 \%(15.9 \%$ to $17.3 \%)$ \\
\hline RTC driver or passenger & 1697 & $12.0 \%(11.5 \%$ to $12.5 \%)$ & 222 & $2.0 \%(1.8 \%$ to $2.2 \%)$ \\
\hline RTC cyclist or pedestrian & 3018 & $21.3 \%(20.6 \%$ to $22.0 \%)$ & 873 & $8.0 \%(7.5 \%$ to $8.4 \%)$ \\
\hline Other & 4806 & $9.2 \%(8.7 \%$ to $9.7 \%)$ & 363 & $1.7 \%(1.4 \%$ to $1.9 \%)$ \\
\hline \multicolumn{5}{|l|}{ Outcome } \\
\hline \multicolumn{5}{|l|}{ Mortality by AIS level } \\
\hline 3 & 89 & $2.2 \%(1.7 \%$ to $2.6 \%)$ & 200 & $11.1 \%(9.6 \%$ to $12.5 \%)$ \\
\hline 4 & 220 & $4.7 \%(4.1 \%$ to $5.4 \%)$ & 724 & $16.3 \%(15.2 \%$ to $17.4 \%)$ \\
\hline 5 & 996 & $27.7 \%(26.2 \%$ to $29.2 \%)$ & 2032 & $48.9 \%(47.4 \%$ to $50.4 \%)$ \\
\hline Overall mortality & 1305 & $10.5 \%(10.0 \%$ to $11.1 \%)$ & 2956 & $28.4 \%(27.5 \%$ to $29.3 \%)$ \\
\hline
\end{tabular}

criterion, although in practice this is seldom used in isolation to drive bypass to the MTC. Indeed, a recent study using the US national trauma registry highlighted the specific risk of under-triage of elderly patients with $\mathrm{TBI}^{20}$ In a UK MTC

Table 2 Comparison of initial GCS between young and older patients by severity of traumatic brain injury (abbreviated injury score (AIS)) and mechanism of injury

\begin{tabular}{|c|c|c|c|c|c|c|}
\hline \multirow[b]{2}{*}{$\begin{array}{l}\text { Mechanism } \\
\text { of injury }\end{array}$} & \multirow[b]{2}{*}{$\begin{array}{l}\text { AIS } \\
\text { head }\end{array}$} & \multicolumn{2}{|c|}{ Age under 65} & \multicolumn{2}{|c|}{ Age 65 or older } & \multirow[b]{2}{*}{ p Value } \\
\hline & & $\mathbf{N}$ & $\begin{array}{l}\text { Median } \\
\text { (IQR) GCS }\end{array}$ & $\mathrm{N}$ & $\begin{array}{l}\text { Median } \\
\text { (IQR) GCS }\end{array}$ & \\
\hline Fall $<2 \mathrm{~m}$ & $\begin{array}{l}3 \\
4 \\
5\end{array}$ & $\begin{array}{r}695 \\
1205 \\
965\end{array}$ & $\begin{array}{l}13(13-15) \\
14(12-15) \\
13(7-15)\end{array}$ & $\begin{array}{l}1136 \\
3328 \\
3155\end{array}$ & $\begin{array}{l}15(14-15) \\
15(14-15) \\
14(10-15)\end{array}$ & $\begin{array}{l}<0.001 \\
<0.001 \\
<0.001\end{array}$ \\
\hline Fall $>2 \mathrm{~m}$ & $\begin{array}{l}3 \\
4 \\
5\end{array}$ & $\begin{array}{l}738 \\
966 \\
781\end{array}$ & $\begin{array}{l}14(11-15) \\
13(8-15) \\
8(3-13)\end{array}$ & $\begin{array}{l}385 \\
734 \\
700\end{array}$ & $\begin{array}{l}14(12-15) \\
14(11-15) \\
10(5-14)\end{array}$ & $\begin{array}{r}0.548 \\
<0.001 \\
<0.001\end{array}$ \\
\hline $\begin{array}{l}\text { RTC-driver/ } \\
\text { passenger }\end{array}$ & $\begin{array}{l}3 \\
4 \\
5\end{array}$ & $\begin{array}{l}639 \\
578 \\
480\end{array}$ & $\begin{array}{r}14(9-15) \\
12(7-14) \\
7(4-12)\end{array}$ & $\begin{array}{l}71 \\
89 \\
62\end{array}$ & $\begin{array}{l}15(12-15) \\
14(13-15) \\
14(10-15)\end{array}$ & $\begin{array}{r}0.009 \\
<0.001 \\
<0.001\end{array}$ \\
\hline $\begin{array}{l}\text { RTC- } \\
\text { pedestrian/ } \\
\text { cyclist }\end{array}$ & $\begin{array}{l}3 \\
4 \\
5\end{array}$ & $\begin{array}{r}1041 \\
1104 \\
873\end{array}$ & $\begin{array}{l}14(11-15) \\
14(8-15) \\
8(4-14)\end{array}$ & $\begin{array}{l}210 \\
343 \\
320\end{array}$ & $\begin{array}{l}14(12-15) \\
14(10-15) \\
11(5-14)\end{array}$ & $\begin{array}{r}0.196 \\
0.382 \\
<0.001\end{array}$ \\
\hline Other & $\begin{array}{l}3 \\
4 \\
5\end{array}$ & $\begin{array}{l}1498 \\
1512 \\
1071\end{array}$ & $\begin{array}{l}14(11-15) \\
14(9-15) \\
10(5-14)\end{array}$ & $\begin{array}{r}79 \\
146 \\
178\end{array}$ & $\begin{array}{l}14(12-15) \\
14(11-15) \\
14(7-15)\end{array}$ & $\begin{array}{l}0.466 \\
0.008 * \\
<0.001\end{array}$ \\
\hline Overall & $\begin{array}{l}3 \\
4 \\
5\end{array}$ & $\begin{array}{l}4611 \\
5365 \\
4170\end{array}$ & $\begin{array}{c}14(11-15) \\
14(9-15) \\
9(4-14)\end{array}$ & $\begin{array}{l}1881 \\
4640 \\
4415\end{array}$ & $\begin{array}{l}15(13-15) \\
14(13-15) \\
14(8-15)\end{array}$ & $\begin{array}{l}<0.001 \\
<0.001 \text { * } \\
<0.001\end{array}$ \\
\hline
\end{tabular}

*Significance is due to distribution/spread. serving a population with a high proportion of elderly patients, the sensitivity of the local triage tool to detect major trauma is reported to be as low as $52 \% .{ }^{21}$ This tool specifies a GCS motor score of $<4$ as the threshold for transportation directly to the MTC. From our data, this threshold would fail to identify the majority of elderly patients with significant TBI, and even those with the most severe TBI (AIS 5) in whom the median presenting GCS was 14; this group has an in-hospital mortality of $49 \%$.

Second, if the GCS in older patients does not reflect the severity of injury as accurately as it does in younger patients, this may partly explain previous observations describing worse outcome following TBI in this group. To achieve the same drop in GCS as younger patients, a greater severity of injury is required, so it is perhaps unsurprising that ultimate outcomes from operative and non-operative care are poorer. However, it has been suggested that intervention in elderly patients with TBI may not be as futile as once thought. ${ }^{7}$

In Hong Kong, 32\% of multiple trauma patients aged $>65$ years undergoing neurosurgery for TBI achieved a good outcome (Glasgow outcome score 4 or 5) at 6 months. ${ }^{8}$ Meanwhile, in a larger cohort of patients undergoing craniotomy for TBI in Michigan, Lau et al reported that patients aged $>80$ years were as likely to return to baseline levels of function as their younger counterparts. The rate of postoperative complication was higher in the extreme elderly but there was no significant difference in 30-day mortality. ${ }^{9}$ In Europe, neurocritical care in the 'younger elderly' (65-75 years) with a GCS of 6-8 was shown to improve survival following $\mathrm{TBI}^{10}$ and outcomes from operative intervention in patients with a GCS $>8$ were as good as in younger patients. ${ }^{11}$ Indeed, outcomes for elderly 
Table 3 Comparison of initial GCS between young and older patients by type of traumatic brain injury and severity (abbreviated injury score (AIS))

\begin{tabular}{|c|c|c|c|c|c|c|}
\hline \multirow[b]{2}{*}{ Intracranial injury type } & \multirow[b]{2}{*}{ AIS head } & \multicolumn{2}{|c|}{ Age under 65} & \multicolumn{2}{|c|}{ Age 65 or older } & \multirow[b]{2}{*}{ p Value } \\
\hline & & $\mathbf{N}$ & Median (IQR) GCS & $\mathbf{N}$ & Median (IQR) GCS & \\
\hline \multirow[t]{3}{*}{ Extradural haematoma } & 3 & & & & & \\
\hline & 4 & 323 & $14(10-15)$ & 114 & $15(14-15)$ & $<0.001$ \\
\hline & 5 & 162 & $14(8-15)$ & 32 & $14(11.5-15)$ & 0.356 \\
\hline \multirow[t]{3}{*}{ Subdural haematoma } & 3 & & & & & \\
\hline & 4 & 511 & $14(10-15)$ & 1166 & $15(14-15)$ & $<0.001$ \\
\hline & 5 & 217 & $12(5-15)$ & 623 & $14(12-15)$ & $<0.001$ \\
\hline \multirow[t]{3}{*}{ Contusion } & 3 & 806 & $14(9-15)$ & 358 & $15(13-15)$ & $<0.001$ \\
\hline & 4 & 11 & $14(8-15)$ & 8 & $14(11.5-15)$ & 0.84 \\
\hline & 5 & 25 & $12(6-15)$ & 10 & $13(11-14)$ & 0.788 \\
\hline \multirow[t]{3}{*}{ Subarachnoid haemorrhage } & 3 & 361 & $14(11-15)$ & 470 & $15(14-15)$ & $<0.001$ \\
\hline & 4 & & & & & \\
\hline & 5 & & & & & \\
\hline \multirow[t]{3}{*}{ Diffuse axonal injury } & 3 & & & & & \\
\hline & 4 & 5 & $4(3-8)$ & 0 & & $\mathrm{~N} / \mathrm{A}$ \\
\hline & 5 & 80 & $7(5-10)$ & 9 & $13(7-15)$ & 0.04 \\
\hline \multirow[t]{3}{*}{ Multiple/mixed } & 3 & 207 & $14(10-15)$ & 153 & $14(13-15)$ & $<0.001$ * \\
\hline & 4 & 559 & $14(9-15)$ & 638 & $14(13-15)$ & $<0.001^{*}$ \\
\hline & 5 & 244 & $10(5-14)$ & 259 & $13(9-15)$ & $<0.001$ \\
\hline
\end{tabular}

patients sustaining moderate and severe TBI have steadily improved over the last 20 years. $^{22}$

In our study, the rate of neurosurgical intervention in the elderly was less than half that of their younger counterparts, while overall mortality was nearly three times higher. With adequate resources, timely neurosurgery, access to neurocritical care and aggressive neurorehabilitation, functional outcomes in the elderly may be just as good as in the young. ${ }^{7}$

The findings of this study cannot be attributed simply to differences in the mechanisms of injury between each group. While elderly patients were more likely to have been injured in a low-energy fall, the same pattern of higher GCS at each level of injury severity was observed consistently across all mechanisms of injury with the greatest difference occurring in the RTC group, either as a pedestrian or cyclist hit by car, or as an occupant of the vehicle. This may be explained by elderly patients being more likely to drive at conservative speeds, resulting in a lower-energy impact, but further work will be required to fully explain the observation.

It has previously been suggested that female gender may have a detrimental impact on outcomes in TBI. ${ }^{23}$ It is difficult to envisage the biological mechanism underlying such an observation, particularly given the likely positive effect of progesterone on neuroinflammation during the evolution of TBI. ${ }^{24}$ In our large study, gender did not independently influence GCS. Since the proportion of women in the head-injured population increases with age and modelling of outcome in TBI relies heavily on presenting GCS, the earlier meta-analysis from which this observation derives may have been confounded if the relationship between age and GCS was not considered.

It is unlikely that the influence of age on GCS is exerted through preponderance of one particular type of intracranial injury in the elderly. Subdural haematomas are more common in the elderly and tend to evolve more slowly, which could result in a higher initial GCS on presentation. We could not determine from the TARN data whether or not a subdural haemorrhage was acute or acute on chronic, which may be better tolerated and is more common in the elderly. In our analysis of 7351 cases with specific types of isolated intracranial injury, 34\% had suffered a subdural haematoma with the majority of these (71\%) being in the elderly group. However, in the elderly group initial GCS was similar at each level of injury severity across all types of isolated intracranial injuries. The greatest difference in presenting GCS between the two groups was for mixed injury. While we found no evidence of a disproportionate effect of any one type of injury, the relatively small number of cases limits the applicability of these findings.

It is possible that cerebral atrophy in the elderly allows a greater volume of blood and oedema to be accommodated following head injury before intracranial pressure rises and GCS falls. Our study cannot answer this question; the AIS is a relatively imprecise measure of the degree of anatomical injury. Future work using advanced imaging techniques might explore the relationship between volume of injured tissue, haematoma and GCS.

Our study has several important limitations inherent in the design of retrospective database analyses. In particular, although we have used an accepted definition of isolated head injury we cannot completely exclude the possible influence of extracranial injury or medical comorbidity on presenting GCS. Also, the eligibility criteria for inclusion on the TARN database may have excluded some younger patients with TARN-qualifying injuries but high GCS who were treated and discharged in under $72 \mathrm{~h}$. There were some minor modifications to the AIS affecting how TBI is coded in 2005, although the majority of cases in the TARN database have been entered since this date. To obtain sufficient numbers for meaningful subgroup analysis, we have included cases entered prior to this date.

\section{CONCLUSION}

This is the largest study to date confirming that for a given anatomical severity of TBI, older patients present with a higher GCS than younger patients. To identify significant TBI in older patients, trauma triage guidelines may need adaptation to ensure that elderly patients are managed appropriately. Thresholds for neurosurgical intervention in the elderly may need to be 
reconsidered. These findings may partly explain the poorer outcomes previously observed in elderly patients with TBI since elderly patients with the same GCS as younger patients are likely to have sustained a more severe anatomical injury.

Twitter Follow Antoinette Edwards at @AntoinetteE60

Contributors AK conceived the original idea for the study. $A E, F L, O B$ and $D Y$ contributed to the acquisition and preparation of data and design and interpretation of the analysis. OB performed the statistical analysis. AK, JES and OB prepared the written submission and all authors contributed to revision of the draft.

Competing interests None declared.

Ethics approval TARN holds HRA CAG Section 251 approval for research on anonymised data submitted by member hospitals.

Provenance and peer review Not commissioned; externally peer reviewed.

\section{REFERENCES}

1 Hyder AA, Wunderlich CA, Puvanachandra $P$, et al. The impact of traumatic brain injuries: a global perspective. NeuroRehabilitation 2007;22:341-53.

2 Teasdale G, Murray G, Parker L, et al. Adding up the Glasgow Coma Score. Acta Neurochir Suppl (Wien) 1979;28:13-16.

3 Jennett $B$, Teasdale $G$, Braakman $R$, et al. Predicting outcome in individual patients after severe head injury. Lancet 1976;1:1031-4.

4 Servadei F, Nasi MT, Cremonini AM, et al. Importance of a reliable admission Glasgow Coma Scale score for determining the need for evacuation of posttraumatic subdural hematomas: a prospective study of 65 patients. J Trauma 1998;44:868-73

5 Kehoe A, Smith JE, Edwards $A$, et al. The changing face of major trauma in the UK. Emerg Med J 2015;32:911-15.

6 Yates DW. The NICE head injury guidelines. Emerg Med J 2003;20:117.

7 Mak CH, Wong SK, Wong GK, et al. Traumatic Brain Injury in the Elderly: Is it as Bad as we Think? Curr Trans/ Geriatr Exp Gerontol Rep 2012;1:171-8.

8 Wong GK, Graham CA, Ng E, et al. Neurological outcomes of neurosurgical operations for multiple trauma elderly patients in Hong Kong. J Emerg Trauma Shock 2011;4:346-50.

9 Lau D, El-Sayed AM, Ziewacz JE, et al. Postoperative outcomes following closed head injury and craniotomy for evacuation of hematoma in patients older than 80 years. J Neurosurg 2012;116:234-45.
10 Patel HC, Bouamra O, Woodford M, et al. Clinical article: mortality associated with severe head injury in the elderly. Acta Neurochir (Wien) 2010;152:1353-7; discussion 7.

11 Bouras T, Stranjalis G, Korfias S, et al. Head injury mortality in a geriatric population: differentiating an "edge" age group with better potential for benefit than older poor-prognosis patients. J Neurotrauma 2007:24:1355-61.

12 Nakamura Y, Daya M, Bulger EM, et al. Evaluating age in the field triage of injured persons. Ann Emerg Med 2012;60:335-45.

13 Salottolo K, Levy AS, Slone DS, et al. The effect of age on glasgow coma scale score in patients with traumatic brain injury. JAMA Surg 2014;149:727-34.

14 Kehoe A, Rennie S, Smith JE. Glasgow Coma Scale is unreliable for the prediction of severe head injury in elderly trauma patients. Emerg Med $J$ 2015;32:613-5.

15 Conover WJI, Iman RL. Rank transformations as a bridge between parametric and nonparametric statistics. Am Stat 1981;35:124-9.

16 Hart A. Mann-Whitney test is not just a test of medians: differences in spread can be important. BMJ 2001;323:391-3.

17 Sasser SM, Hunt RC, Faul M, et al. Guidelines for field triage of injured patients: recommendations of the National Expert Panel on Field Triage, 2011. MMWR Recomm Rep 2012;61(RR-1):1-20.

18 Caterino JM, Raubenolt A, Cudnik MT. Modification of Glasgow Coma Scale criteria for injured elders. Acad Emerg Med 2011;18:1014-21.

19 Ichwan B, Darbha S, Shah MN, et al. Geriatric-specific triage criteria are more sensitive than standard adult criteria in identifying need for trauma center care in injured older adults. Am J Emerg Med 2015; 65:92-100.e3.

20 Xiang $\mathrm{H}$, Wheeler KK, Groner Jl, et al. Undertriage of major trauma patients in the US emergency departments. Am J Emerg Med 2014;32:997-1004.

21 Potter D, Kehoe A, Smith JE. The sensitivity of pre-hospital and in-hospital tools for the identification of major trauma patients presenting to a major trauma centre. J R Nav Med Serv 2013;99:16-19.

22 Ramanathan DM, McWilliams N, Schatz P, et al. Epidemiological shifts in elderly traumatic brain injury: 18-year trends in Pennsylvania. J Neurotrauma 2012;29:1371-8

23 Farace $E$, Alves WM. Do women fare worse: a metaanalysis of gender differences in traumatic brain injury outcome. J Neurosurg 2000;93:539-45.

24 Pascual JL, Murcy MA, Li S, et al. Neuroprotective effects of progesterone in traumatic brain injury: blunted in vivo neutrophil activation at the blood-brain barrier. Am J Surg 2013;206:840-5; discussion 5-6. 